\title{
Medical thoracoscopy
}

\section{Cyrus Daneshvar • David P. Breen}

Published online: 9 January 2013

(C) Springer Science+Business Media New York 2013 more operator-friendly by improving the endoscopic view by induction of a pneumothorax at the onset of the procedure [2].

The term thoracoscopy encompasses a range of procedures, including those performed by the physician (medical thoracoscopy, pleuroscopy, or local anaesthetic thoracoscopy) and, more recently, the emergence of "video-assisted thoracoscopic surgery" (VATS) performed by surgeons. The procedure undertaken by pulmonologists is usually performed in the endoscopy suite under local anaesthesia and with intravenous conscious sedation and/or analgesia, whereas VATS requires general anaesthesia and double lumen tracheal intubation in the operating room. The range of indications and intervention performed differ between the two procedures. Medical thoracoscopy is frequently indicated for diagnostic purposes (pleural effusions) and for talc pleurodesis ("poudrage") to prevent recurrence of persistent pleural effusions or pneumothorax. Surgeons using VATS perform more advanced procedures, including pulmonary nodule resection and lobectomies.

\section{Indications}

Although the basic technique of thoracoscopy is standard worldwide, the range of indications varies depending on the resources, experience, and skills of the operator. The common indications reported in the literature are listed in Table 1.

Although Jacobaeus is credited with the development of thoracoscopy, the first literature report was that of Samuel Gordon who, in 1866, described exploration of the pleural cavity of an 11-year-old girl with empyema [1]. This first procedure was performed in 1865 by the Irish physician Francis Richard Cruise. However, it was Jacobaeus who made the procedure

C. Daneshvar

Department of Respiratory Medicine,

Galway University Hospitals, Galway, Ireland

D. P. Breen $(\square)$

Respiratory Physician, Clinical Lead for Lung Cancer Services, Galway University Hospitals, Galway, Ireland

e-mail: david.breen@hse.ie

\section{Equipment and training}

A detailed description of thoracoscopy technique can be found in recent reviews, and is beyond the scope of this review article [3, 4]. Thoracoscopy should be performed in a suitable clinical environment with appropriate facilities to maintain "surgical equivalent" sterile technique. The standard operating equipment required for thoracoscopy includes a boutin needle, a trocar consisting of an obturator and a canula, a directviewing and angle-viewing optical telescope, an optical forceps, and a light source (Fig. 1). In the event of complications, for example haemorrhage, an insulated trocar is necessary for a 
Table 1 Indications for thoracoscopy

\begin{tabular}{ll}
\hline Indication & Procedure \\
\hline Diagnostic & $\begin{array}{l}\text { Diagnosis of an undiagnosed exudative pleural effusion } \\
\text { Diagnosis and staging of malignant mesothelioma } \\
\text { Diagnosis and staging of lung cancer } \\
\text { Therapeutic }\end{array}$ \\
& $\begin{array}{l}\text { Talc poudrage } \\
\text { Management of empyema }\end{array}$ \\
& $\begin{array}{l}\text { Management of spontaneous pneumothorax } \\
\text { Lung biopsy }\end{array}$ \\
& $\begin{array}{l}\text { Mediastinal biopsy } \\
\text { Diaphragmatic } \\
\text { Pericardial biopsy/window }\end{array}$ \\
\hline
\end{tabular}

second port through which electrocautery can be performed. Additional necessary equipment is listed in Table 2. Thoracic ultrasound (TUS) is preferable before induction of pneumothorax, because it identifies a safe site of entry, even in complex pleural spaces $[5,6]$.

The optimum diameter of the thoracoscope (trocar and telescope) is $7 \mathrm{~mm}$, as originally developed by Boutin in conjunction with the Wolff Corporation ( Knittlingen, Germany). Larger telescopes (diameter 10-12 mm) are available but have been developed with the surgeon in mind and in which the procedure will be performed under general anaesthesia and double lumen intubation. However, they are impractical for a procedure performed under local anaesthesia.

More recently, such techniques as minithoracoscopy and flexi-rigid thoracoscopy have been described in the literature. Minithoracoscopy, using a $2-5 \mathrm{~mm}$ trocar has promising diagnostic yields; it enables adequate visualization of the pleural space but takes longer to perform and may encounter difficulties with the management of adhesions [7]. Tassi et al. achieved a diagnostic yield of $93 \%$ by use of a $3 \mathrm{~mm}$ thoracoscope [8]. In a paper comparing 2-mm, 3-mm, and standard thoracoscopes, the authors achieved diagnostic yields of $40 \%, 100 \%$, and $100 \%$ for the $2-\mathrm{mm}, 3-\mathrm{mm}$, and 7-mm equipment, respectively [9].

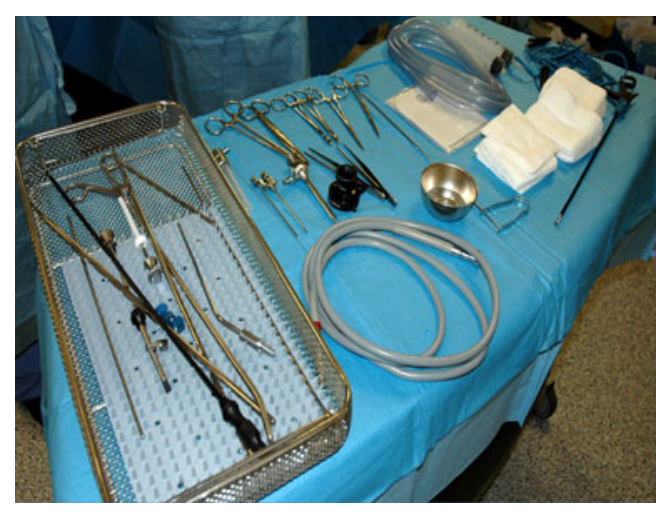

Fig. 1 Equipment set up for thoracoscopy
Table 2 Essential equipment for thoracoscopy

A suitable area for surgical scrubbing, sterile gowns, sheets, and gloves

A thoracoscopy table

Separate mobile carts

A Mayo stand for the instruments - covered with sterile sheets

Monitoring equipment including ECG, blood pressure and saturation

Needles $-24 \mathrm{G}$ and $21 \mathrm{G}$ for administration of local anaesthetic agents

$110-\mathrm{mL}$ and $50-\mathrm{mL}$ syringes

Surgical swabs

Scalpel

Clamps

Grasping forceps and a swab holder

Sterile covers for the cables attaching the optics and camera to the lighting source

Plastic sterile aspiration tubes, 4 and $6 \mathrm{~mm}$ in diameter

Aspiration tubing and collection bottles of at least 2 litre capacity

Cupulas for local anaesthetic (LA), warm saline - used to prevent fogging of the optics - and soap

Chest drains ranging from size 20 to $32 \mathrm{fr}$

A guide for the chest drain or a self contained chest tube set with an inner stylet

The semi-rigid and/or flexible thoracoscope has advantages and disadvantages compared with traditional rigid thoracoscopy. Although the rigid thoracoscope enables excellent vision, large biopsy samples using a single port of entry, ease of biopsy from harder lesions, and easy orientation inside the pleural cavity, the flexible equipment enables lateral vision or retrovisualization (which would require a separate obliqueview telescope when using rigid instruments), while maintaining high diagnostic yield $[10,11]$. In addition, physicians who are skilled with the flexible bronchoscope may feel more comfortable with the semi-rigid thoracoscope.

It is mandatory that the operator is skilled in the technique of thoracoscopy and has an excellent command of pleural anatomy and the associated landmarks. The optimum way of learning often starts with a practical course incorporating a theoretical component (organized courses are available in Europe and the USA). The American College of Chest Physicians published their interventional pulmonary procedures guideline in 2003, these recommendations advise a minimum of 20 procedures in a supervised setting to ensure basic competence and at least 10 procedures per year to maintain competence [12]. However it is our opinion that a period of mentoring in a busy thoracoscopy service is preferable before commencing independent practice. In addition, all supporting staff should be well versed in the procedure and comfortable with all aspects of the equipment.

The vast majority of procedures, including talc poudrage, can be performed through a single port of entry if the initial trocar size is at least $5 \mathrm{~mm}$ in diameter. A second port of entry is occasionally indicated. This point of entry is located one 
intercostal space superior or inferior to the primary port of entry or in the setting of haemorrhage, located to enable electrocoagulation of the site of bleeding. Indications for a second port include situations where the movement of the trocar is sufficiently painful to prevent a full inspection of the area of interest. This complication can be minimized by choosing the position carefully at the outset with the aid of available radiographs, computed tomography (CT), and pre-procedure TUS.

Occasionally, however, simple geographical problems between the entry point and the lesion or a narrow intercostal space prevents complete manoeuvrability of the trocar. Although application of local anaesthesia enables excellent management of the immediate area of entry, it has no effect on the ribs; this may result in pain if they are forcefully pushed up or down by the movement of the thoracoscope. Large adhesions may sometimes prevent full examination of the pleural cavity. If so, a second access point should be created. Finally, if electocautery is needed for haemostasis, the physician must be able to create a second port of entry quickly. This can be placed rapidly under direct vision. The chosen site is viewed through the primary port with the optic while the assistant depresses the preferred second entry site on the chest wall. The external compression can be easily visualized on the internal chest wall and a trocar can be placed rapidly.

\section{Complications}

Thoracoscopy is usually a safe procedure. Mortality is $0.35 \%$ (95\% confidence interval $0.19-0.54 \%$ ), and likely to be less if diagnostic procedures alone are performed [3]. This compares favourably with mortality for transbronchial biopsy $(0.22-0.6 \%)[13,14]$ and mediastinoscopy $(0.17 \%)$ [15]. Major complications (empyema, haemorrhage, port site tumour growth, bronchopleural fistula and/or persistent air leak, postoperative pneumothorax, and pneumonia) occur in $1.8 \%$ (95\% CI 1.4-2.2\%) and minor complications (subcutaneous emphysema, minor haemorrhage, operative skin site infection, fever, and atrial fibrillation) in $7.3 \%$ (95\% CI 6.3-8.4\%) [3].

\section{Update}

The following sections cover recent important advances in the field of thoracoscopy.

\section{Procedural}

Use of thoracic ultrasound in thoracoscopy has been discussed in several papers. Medford et al. reported that after the introduction of pleural ultrasound, success of pleural access improved from $83.7 \%$ to $100 \%(p=0.052)$ [16]. Furthermore, it facilitated identification of adhesions which were poorly detected on $\mathrm{CT}$ scans. Use of thoracic ultrasound to predict the presence of adhesions before thoracoscopy has been assessed in a surgical setting [17, 18]. Both studies demonstrated that ultrasound is effective when used by experienced operators. Medford, in a recent letter published in the journal Respiratory Medicine, emphasized the potential cost benefit of thoracic ultrasound before medical thoracoscopy in an NHS hospital setting [19]. In a cohort of 30 patients undergoing thoracoscopy without thoracic ultrasound, five patients required additional invasive investigation, with an associated significant additional cost. He argues that the cost of implementing thoracic ultrasound before routine medical thoracoscopy would be recovered within a year.

\section{Sedation}

There is limited or no information about the optimum method for sedation or analgesia during medical thoracoscopy [3]. Tschopp et al. discussed the use of propofol by nonanaesthetists in medical thoracoscopy [20]. This was a feasibility and safety study in which 53 patients were enrolled. The duration of the median procedure was $28 \mathrm{~min}$, the median propofol dose required was $145 \mathrm{mg}$, and an additional median dose of $84 \mathrm{mcg}$ fentanyl was administered. Haemodynamic complications were the most common reported adverse event $(n=39)$; including hypotension for 34 patients. However, the dosing algorithm required the use of haemodynamic monitoring and a bi-spectral index, which could make this less appealing to physicians working primarily in endoscopy units without anaesthetic backup.

Agnoletti et al. assessed the feasibility of multilevel thoracic paravertebral blocks (T3-T7) [21]. Defining primary and secondary outcomes, they reported good overall response with few complications. They used $0.2 \mathrm{mg} \mathrm{kg}^{-1}$ midazolam. For the 26 patients enrolled in the study, pain during the procedure and vasovagal syncope for two patients were reported. This is obviously an additional skill requiring supplementary staff to be present at the time of medical thoracoscopy, but is a potential alternative for patients deemed unsuitable for standard methods of sedation and/or analgesia.

\section{Complications}

Physiological response to medical thoracoscopy was assessed by Froudarakis et al. [22]. They measured mean inspiratory and expiratory pressures (MIP and MEP) and lung function pre-procedure and serially post-procedure. They identified an initial reduction in both inspiratory and expiratory pressures and lung function in the first $24 \mathrm{~h}$ after the procedure. A small 
drop in oxygen saturation was also noted. Recovery back to baseline was the norm after a few days.

Despite the reporting of studies which have revealed the safety of talc as a pleurodesis agent, the debate continues [23-26]. Lee discussed the merits of different techniques for management of malignant pleural effusions. Evidence supports talc as the most effective agent for pleurodesis with reported success of 81 to $100 \%$. This compares favourably to other agents, for example tetracycline $(65-76 \%)$ or bleomycin $(61 \%)$. A recent large multicentre study in Europe has confirmed the safety of graded talc for patients with pleural space malignancy. Talc poudrage via thoracoscopy is the preferred choice for pleurodesis with better outcomes than for talc slurry. In addition, poudrage was better tolerated by patients. Indwelling pleural catheters are a viable alternative, particularly for patients who fail chemical pleurodesis. However this technique may not be cost effective if overall life expectancy is greater than six weeks.

Light has reported good results with indwelling pleural catheters compared with chemical pleurodesis. However one of the studies compared the catheter to doxycycline, an inferior agent for pleurodesis compared with talc. In any case, it seems clear that the use of the indwelling pleural catheter results in shorter initial hospital stays and, hence, less cost. This cost saving may not continue if the patient has a prolonged survival because of the need for frequent drainage of fluid. Light also discusses the ongoing concerns about the safety of talc - especially the development of ARDS. However most studies used ungraded talc with smaller particles. Two European multicentre studies enrolling patients with malignant effusions and pneumothorax, respectively, utilized graded talc. These studies found no cases of ARDS. The superiority of poudrage over slurry is also questioned. However it is important to emphasize that thoracoscopy has additional advantages over chest drainage-visualisation of the pleural space, biopsies, removal of adhesions, etc. The debate is likely to continue.

Brims et al. reported outcomes for 58 patients for whom thoracoscopy had been performed over a twelve-month period [27]. Of note, the study geographical area has a high prevalence of mesothelioma because of the proportion of the population with known dockyard exposure. Hospital-acquired infections (pneumonia or empyema) proved to be the most problematic complication, occurring in six $(10.5 \%)$ patients. Infection affected length of stay and prolonged the duration of in-situ chest drainage. Although no deaths occurred in the immediate post-procedure period, four patients died within a month - three of whom had hospital-acquired infections. Mootha et al, reporting retrospective data between 2007 and 2008 in an Indian tertiary referral hospital with a differing range of pleural disease, reported similar incidence of empyema, which occurred in two of 35 cases (5.2\%) [28]. They reported few complications overall — a valuable contribution to the development of this diagnostic procedure in a country where asbestos exposure remains a long-term problem and will become important in the future for undiagnosed exudative pleural effusions [29].

\section{Malignant pleural disease}

In the management algorithm in BTS guidelines, thoracoscopy remains an alternative to intercostal drain insertion and is indicated if there is no evidence of trapped lung, with a view to performing talc poudrage - probably the optimum method for pleurodesis $[30,31]$. The suitability of thoracoscopy for trapped lung is unclear. However, it should be stated that thoracoscopy enables more than simple therapeutic management of the pleural space. It enables visualization of pleural and diaphragmatic surfaces and identification and possible ligation of adhesions which may affect optimum pleurodesis. Indwelling pleural catheters (IPC), placed at the time of the procedure, may be useful for patients who have probable trapped lung at the time of thoracoscopy $[32,33]$. These studies suggest placement of an IPC may be preferable as a single procedure in this difficult to manage population with malignant pleural disease.

An interesting follow up study on patients with fibrinous pleuritis, revealed the incidence of false-negative biopsies was $18 \%$ [34•]. Use of thoracoscopy for visual interpretation of the pleural space, CT findings, and female gender, were all risk factors for malignant disease. These findings were similar to those published by Davies et al., and have recently been the subject of detailed review $[35,36]$.

Metintas et al. reported a randomized study comparing CT-guided Abraham needle biopsy and thoracoscopy biopsy for 124 patients with undiagnosed exudative pleural effusions [37]. Although thoracoscopy had higher sensitivity for malignant disease ( $87 \%$ versus $94.1 \%$, respectively), the difference was not statistically significant. With the increase in pulmonologists utilising thoracic ultrasound and/or thoracoscopy and familiarity performing guided procedures, it is unlikely that CT-guided Abraham needle biopsy will become widely adopted.

\section{Role in staging}

Hubbard et al. reported a small case series in which thoracoscopy was used for assessment of patients with Pancoast tumours without clear radiographic evidence of chest wall invasion [38]. By use of thoracoscopy, invasion was identified in eight of twelve $(75 \%)$ patients, and reduced the time to initiation of definitive treatment (chemotherapy and/or radiotherapy; 22.3 days versus surgery 60 days). Although primarily surgical, Fleury et al. reported use of pre-operative 
thoracoscopy for patients with presumed advanced ovarian carcinoma. Thoracoscopic assessment of the pleural cavity upstaged 27 of 75 patients with stage IIIc ovarian cancer who were initially being considered for cytoreductive surgery before the results from the thoracoscopy [39].

\section{Complicated parapneumonic effusions and empyema}

Although the most recent British Thoracic Society (BTS) guidelines on pleural infection did not envisage use of medical thoracoscopy [40], the BTS local anaesthetic thoracoscopy guideline report acknowledged the procedure may be useful for division of septations and adhesions, thus creating a single pleural cavity and improving drainage [3]. Although the literature reports high success $(91.7 \%)$, these data are derived from case series which lack direct comparisons or a control group [41-43]. Use of medical thoracoscopy in the management of an infected pleural space continues to stimulate debate. Although some believe surgery to be the optimum management, no studies have rigorously addressed this question. As VATS replaces open thoracotomy [44], natural progression to medical thoracoscopy is likely to be inevitable and, indeed, is already relatively common practice in some centres in Europe.

Good data are available on conservative treatment outcomes in the management of pleural-based infection, so difficulties remain in defining when surgery should be performed, and, by extension, when medical thoracoscopy should be included in overall management. It is likely that the timing of the procedure, the complexity of the pleural space, and the skill of the thoracoscopist will affect this. It seems that an interesting transition is occurring in pleural infection, in which management strategies could be moving to different ends of the range-with even more conservative management treatment strategies (involving antibiotics, small or no drains) or immediate pleural clearance under medical thoracoscopy or surgical VATS. No studies have definitively addressed these issues. However, Ravaglia et al. retrospectively reported on six years experience with 41 patients with multiloculated and organized empyema [45]. Overall success of $35(85.4 \%)$ was reported, but success dropped to $50 \%$ for patients defined as having an "organized" empyema. A denominator and clear selection criteria for procedure would be preferable in such a study, but it does seem that in highly selected patients thoracoscopy is an acceptable management choice. Whether there is benefit over more conservative management remains unclear, but in specific situations it should be considered when all options are addressed and balanced. Tassi et al. discussed the use of thoracoscopy in the management of parapneumonic effusions and empyema, and argued that it may be cost-effective and may avoid progression to VATS [46]. Finally it must be borne in mind that thoracoscopy for pleural infection is defined as an advanced procedure by the authors, and should only be undertaken by very experienced pulmonologists.

\section{Pneumothorax}

In Europe use of thoracoscopy early in the management of primary spontaneous pneumothorax is common practice. This is supported by a single randomised study comparing talc poudrage versus intercostal drainage, with recurrence of $5.1 \%$ and $34 \%$, respectively, at five years [47]. However the BTS guidelines recommend surgical referral on the basis that it is a definitive procedure with good results and a greater range of therapeutic options [48]. Comparative studies of use of medical thoracoscopy versus VATS thoracoscopy are required, and are the subject of current research [49••].

\section{Education}

As new techniques become available in interventional thoracic medicine, training remains a pertinent issue. Holt et al. reported a study on the educational effectiveness of a thoracoscopy short course [50]. Pre-course and post-course examinations, assessing both cognitive and technical skills, resulted in significant improvements in this self-selecting group of pulmonologists who had no formal training in thoracoscopy. Meanwhile, integration of a thoracoscopy video-based educational tool for anatomy undergraduates proved more beneficial than small group lectures, with nearly $70 \%$ of students perceiving benefit [51]. Clearly, a combined approach of visual and/or spatial stimulation and practical engagement coupled with core knowledge will ensure that participants benefit maximally from short courses. However, a period of mentoring will always be required before participants become independent in this procedure.

\section{Conclusion}

Medical thoracoscopy is a growing field in interventional pulmonology, with an increasing number of physicians performing the technique. With the increasing availability of this minimally invasive procedure it is imperative that good practice is maintained via ongoing audit. Key research questions must be addressed in multicentred studies, and new techniques should be evaluated to improve the safety and efficacy of the procedure and provide better clinical outcomes for patients with pleural disease - both benign and malignant.

Disclosure No potential conflicts of interest relevant to this article were reported. 


\section{References}

Papers of particular interest, published recently have been highlighted as:

- Of importance

- Of major importance

1. Gordon S. Case in which the operation of Trephining of the Spine was performed. Med Chir Trans. 1866;49:21-8.

2. Jacobaeus HC. Uber die Moglichkeit die Zystoskopie bei Untersuchung seroser Hohlungen anzuwenden [About the possibility to apply the cystoscopy in the investigation of serous cavities]. Munch Med Woch. 1910;57:2090-2.

3. Rahman NM, et al. Local anaesthetic thoracoscopy: British thoracic society pleural disease guideline 2010. Thorax. 2010;65 Suppl 2:ii54-60.

4. Rodriguez-Panadero F. Medical thoracoscopy. Respiration. 2008;76(4):363-72.

5. Macha HN, et al. The role of ultrasound assisted thoracoscopy in the diagnosis of pleural disease. Clinical experience in 687 cases. Eur J Cardiothorac Surg. 1993;7(1):19-22.

6. Hersh CP, et al. Ultrasound guidance for medical thoracoscopy: a novel approach. Respiration. 2003;70(3):299-301.

7. Tassi GF, Marchetti GP, Pinelli V. Minithoracoscopy: a complementary technique for medical thoracoscopy. Respiration. 2011; 82(2):204-6.

8. Tassi G, Marchetti G. Minithoracoscopy: a less invasive approach to thoracoscopy. Chest. 2003;124(5):1975-7.

9. Janssen JP, Thunnissen FBJM, Visser FJ. Comparison of the $2.0 \mathrm{~mm}$ and $3.5 \mathrm{~mm}$ minithoracoscopy set to standard equipment for medical thoracoscopy. Eur Respir J. 2003;22 Suppl 45:S541.

10. Lee P, et al. Prospective evaluation of flex-rigid pleuroscopy for indeterminate pleural effusion: accuracy, safety and outcome. Respirology. 2007;12(6):881-6.

11. Munavvar M, et al. The autoclavable semirigid thoracoscope: the way forward in pleural disease? Eur Respir J. 2007;29(3):571-4.

12. Ernst A, Silvestri GA, Johnstone D. Interventional pulmonary procedures: guidelines from the American college of chest physicians. Chest. 2003;123(5):1693-717.

13. Andersen HA, Fontana RS. Transbronchoscopic lung biopsy for diffuse pulmonary diseases: technique and results in 450 cases. Chest. 1972;62(2):125-8.

14. Zavala DC. Pulmonary hemorrhage in fiberoptic transbronchial biopsy. Chest. 1976;70(5):584-8.

15. Wall CP, et al. Comparison of transbronchial and open biopsies in chronic infiltrative lung diseases. Am Rev Respir Dis. 1981; 123(3):280-5.

16. Medford AR, et al. Thoracic ultrasound prior to medical thoracoscopy improves pleural access and predicts fibrous septation. Respirology. 2010;15(5):804-8.

17. Wei $\mathrm{B}$, et al. Use of transthoracic ultrasound to predict pleural adhesions: a prospective blinded study. Thorac Cardiovasc Surg. 2012;60(2):101-4.

18. Cassanelli N, et al. Accuracy of transthoracic ultrasound for the detection of pleural adhesions. Eur J Cardiothorac Surg. 2012;42(5):813-8.

19. Medford AR. Additional cost benefits of chest physician-operated thoracic ultrasound (TUS) prior to medical thoracoscopy (MT). Respir Med. 2010;104(7):1077-8.

20. Tschopp JM, et al. Titrated sedation with propofol for medical thoracoscopy: a feasibility and safety study. Respiration. 2011;82 (5):451-7.

21. Agnoletti V, et al. Efficacy and safety of thoracic paravertebral block for medical thoracoscopy. Br J Anaesth. 2011; 106(6):916-7.
22. Froudarakis ME, et al. Respiratory muscle strength and lung function in patients undergoing medical thoracoscopy. Respiration. 2010;80(3):220-7.

23. Bridevaux PO, et al. Short-term safety of thoracoscopic talc pleurodesis for recurrent primary spontaneous pneumothorax: a prospective European multicentre study. Eur Respir J. 2011;38(4):770-3.

24. Janssen JP, et al. Safety of pleurodesis with talc poudrage in malignant pleural effusion: a prospective cohort study. Lancet. 2007;369(9572):1535-9.

25. Lee P. Point: should thoracoscopic talc pleurodesis be the first choice management for malignant effusion? Yes. Chest. 2012; 142(1):15-7. discussion 20-1.

26. Light RW. Counterpoint: should thoracoscopic talc pleurodesis be the first choice management for malignant pleural effusion? No. Chest. 2012;142(1):17-9. discussion 19-20.

27. Brims FJ, Arif M, Chauhan AJ. Outcomes and complications following medical thoracoscopy. Clin Respir J. 2012;6(3):144-9.

28. Mootha VK, et al. Medical thoracoscopy for undiagnosed pleural effusions: experience from a tertiary care hospital in north India. Indian J Chest Dis Allied Sci. 2011;53(1):21-4.

29. Burki T. Health experts concerned over India's asbestos industry. Lancet. 2010;375(9715):626-7.

30. Shaw, P. and R. Agarwal. Pleurodesis for malignant pleural effusions. Cochrane Database Syst Rev. 2004;(1):CD002916. Review

31. Tan $\mathrm{C}$, et al. The evidence on the effectiveness of management for malignant pleural effusion: a systematic review. Eur J Cardiothorac Surg. 2006;29(5):829-38.

32. Reddy C, et al. Rapid pleurodesis for malignant pleural effusions: a pilot study. Chest. 2011;139(6):1419-23.

33. Schneider T, et al. Recurrent pleural effusion: who benefits from a tunneled pleural catheter? Thorac Cardiovasc Surg. 2009;57(1):42-6.

34. - Metintas M, et al. Outcome of patients diagnosed with fibrinous pleuritis after medical thoracoscopy. Respir Med. 2012; 106(8):1177-83. This paper discusses a major issue in thoracoscopy-diagnosis of pleuritis post biopsy. This, with Refs. [35] and [36], address issues re diagnosis and follow up of the patient population.

35. Wrightson JM, Davies HE. Outcome of patients with nonspecific pleuritis at thoracoscopy. Curr Opin Pulm Med. 2011;17(4):242-6.

36. Davies HE, et al. Outcome of patients with nonspecific pleuritis/ fibrosis on thoracoscopic pleural biopsies. Eur J Cardiothorac Surg. 2010;38(4):472-7.

37. Metintas M, et al. Medical thoracoscopy vs CT scan-guided Abrams pleural needle biopsy for diagnosis of patients with pleural effusions: a randomized, controlled trial. Chest. 2010;137 (6): $1362-8$.

38. Hubbard MO, Schroeder C, Linden PA. Routine use of staging thoracoscopy for pancoast tumors without overt radiographic chest wall invasion. Surg Laparosc Endosc Percutan Tech. 2011;21(2):111-5.

39. Fleury AC, et al. Upper abdominal cytoreduction and thoracoscopy for advanced epithelial ovarian cancer: unanswered questions and the impact on treatment. BJOG. 2012;119(2):202-6.

40. Davies HE, Davies RJ, Davies CW. Management of pleural infection in adults: British thoracic society pleural disease guideline 2010. Thorax. 2010;65 Suppl 2:ii41-53.

41. Brutsche MH, et al. Treatment of sonographically stratified multiloculated thoracic empyema by medical thoracoscopy. Chest. 2005;128(5):3303-9.

42. Soler M, et al. Treatment of early parapneumonic empyema by "medical" thoracoscopy. Schweiz Med Wochenschr. 1997; 127(42):1748-53.

43. Colt HG. Thoracoscopy. A prospective study of safety and outcome. Chest. 1995;108(2):324-9.

44. Angelillo Mackinlay TA, et al. VATS debridement versus thoracotomy in the treatment of loculated postpneumonia empyema. Ann Thorac Surg. 1996;61(6):1626-30. 
45. Ravaglia C, et al. Is medical thoracoscopy efficient in the management of multiloculated and organized thoracic empyema? Respiration. 2012;84(3):219-24.

46. Tassi GF, Davies RJ, Noppen M. Advanced techniques in medical thoracoscopy. Eur Respir J. 2006;28(5):1051-9.

47. Tschopp JM, et al. Talcage by medical thoracoscopy for primary spontaneous pneumothorax is more cost-effective than drainage: a randomised study. Eur Respir J. 2002;20(4):1003-9.

48. MacDuff A, Arnold A, Harvey J. Management of spontaneous pneumothorax: British thoracic society pleural disease guideline 2010. Thorax. 2010;65 Suppl 2:ii18-31.
49. • Tschopp JM, et al. VATS or simple talc poudrage under medical thoracoscopy for recurrent spontaneous pneumothorax. Eur Respir J. 2009;33(2):442-3. This paper gives further evidence supporting the overall safety profile of graded talc.

50. Colt HG, et al. Use of competency-based metrics to determine effectiveness of a postgraduate thoracoscopy course. Respiration. 2010; 80(6):553-9.

51. Alnassar SA, et al. The use of thoracoscopy to enhance medical students' interest and understanding of thoracic anatomy. Ann Thorac Med. 2012;7(3):145-8. 